\title{
2. ADVANCES IN HARD-ROCK DRILLING AND CORING TECHNIQUES, ODP LEG $118^{1}$
}

\author{
Steven P. Howard ${ }^{2}$
}

\section{INTRODUCTION}

During Leg 118, 12 shallow exploratory holes were cored in the Atlantis II Transform on the Southwest Indian Ridge. These holes were drilled using the 9.5 -in. positive displacement coring motors (PDCM) on the sides and bottom of the transform valley in $3000-5000 \mathrm{~m}$ of water. All holes were spudded using newly developed drilling hardware and techniques, with little or no bottom-hole assembly (BHA) support and stabilization.

The information obtained by drilling these exploratory holes using the 9.5-in. coring motors helped to select Site 735, where a hard-rock guidebase (HRGB) was set. A guidebase was deployed in $731 \mathrm{~m}$ of water. During an 18-day drilling period, $500 \mathrm{~m}$ of gabbro was cored in Hole 735B. A total of $434 \mathrm{~m}$ of core was recovered for an average recovery rate of $87 \%$.

The time spent conducting unsupported exploratory coring allowed us to field test extensively these 9.5 -in. coring motors. Running the guidebase, testing the core bit extensively in Hole $735 \mathrm{~B}$, and deploying the navidrill resulted in significant increases in knowledge and experience in hard-rock drilling. The Ocean Drilling Program (ODP) will use the results of this hardware development during Leg 118 as key building blocks for future development of crustal coring systems designed to drill and core fractured hard-rock formations.

\section{EASTMAN-CHRISTENSEN 9.5-IN. POSITIVE DISPLACEMENT CORING MOTOR}

\section{Overview of Unsupported Spudding Operations in Leg 118 Single-Bit Holes}

Twelve shallow holes were spudded at Sites 732, 733, 734, and 735 using Eastman Christensen's 9.5-in. positive displacement coring motor (PDCM). The PDCM provides up to 6000 $\mathrm{ft}-\mathrm{lb}$ of torque at 90 to $120 \mathrm{rpm}$. Flow rates of 400 to $600 \mathrm{gal} /$ min are required to rotate the motor downhole. A $30-\mathrm{ft}$ core barrel, run in on wireline, is landed in the hollow rotor section of the motor. This rotor is connected to the drill string through the drive sub assembly. As fluid passes across, rotor and stator torque is generated. This torque rotates the 40 -ft-long outer motor housing, which in turn induces torque and rotation to the 10.5 -in. outside diameter $\times 2.25$-in. roller-cone core bit. After cutting a $30-\mathrm{ft}$ cone, the core barrel is retrieved by wireline, completing the coring cycle (Fig. 1).

The PDCM allows the entire drill string to remain stationary. Only the core bit and motor housing rotate. In addition, because the drill string remains stationary, one can use the newly developed real-time television/sonar system on the drill string to monitor stability of the bottom-hole assembly (BHA) and bit confinement during critical spudding operations. Combining the use of the PDCM with the television/sonar system makes it possible to conduct exploratory coring operations efficiently

\footnotetext{
${ }^{1}$ Robinson, P. T., Von Herzen, R. P., et al., 1989. Proc. ODP, Init. Repts., 118: College Station, TX (Ocean Drilling Program).

2 Ocean Drilling Program, 1000 Discovery Drive, College Station, TX 77840.
}

and reliably with an unsupported BHA (Fig. 2). We lost no BHAs during operations using the PDCM. Before the advent of PDCMs, many BHAs were lost while attempting to spud barerock sites during the Deep Sea Drilling Project.

A total of $142 \mathrm{~m}$ of hole was drilled during 95 hours of rotation. All of these holes were spudded using an unsupported BHA. A total of $9.6 \mathrm{~m}$ of core was recovered. This low core recovery was attributed to coring with an unsupported BHA and to encountering significant amounts of surface rubble at many of the drill sites (see "Introduction and Explanatory Notes" chapter, this volume). Although core recovery was low, we did obtain considerable information about drilling characteristics and formation types in the 12 exploratory holes. This information was used to eliminate undesirable drill sites. The chances of setting a reentry structure (reentry cone and guidebase) on a site where a $200+-m$ scientific objective could be reached during the time allocated for a single drilling leg were enhanced significantly using unsupported coring and drilling techniques.

\section{Unsupported Spudding Procedures}

Rotation of PDCMs was established during spudding with flow rates as low as $150 \mathrm{gal} / \mathrm{min}$, with $5000 \mathrm{lb}$ weight on bit, and with a surface pump pressure of $200 \mathrm{psi}$. Drilling parameters were increased slowly to $600 \mathrm{gal} / \mathrm{min}, 5,000$ to $10,000 \mathrm{lb}$ weight on bit, and 1500 to $1600 \mathrm{psi}$ pump pressure. Flow rates and weight on bit varied owing to seafloor conditions, the amount of sediment or surface rubble present, and the formation being drilled. Drilling parameters increased as a function of increased bit confinement and increased amount of BHA buried below the seafloor.

The coring motor BHA consisted of a 10.5- $\times 2.25$-in. roller cone core bit, a 9.5 -in. coring motor, a crossover sub, five 8.25 in. drill collars, another crossover sub, a 7.25-in. drill collar, a crossover sub, and six stands of 5.5-in. drill pipe. We tried to keep the neutral point in the BHA as low as possible. Typically, $10,000 \mathrm{lb}$ of weight was run on the bit during the initial spudding. The television/sonar system was used to provide immediate feedback about bit confinement and BHA stability-parameters used to govern the amount of motor torque, rotational speed (revolutions per minute), and weight on bit that could be run.

Although the bit remained on bottom during all spudding operations, heave-induced fluctuation of weight on bit could be seen from cyclic torquing of the drill pipe (observed with the television/sonar system) and by fluctuations in pump pressure at the surface. Note that these observed cyclic fluctuations in drillstring torque and indicated surface pump pressure were not always synchronized with the period of ship's heave. A combination of frictional dynamics of the bit may also have contributed to the cyclic fluctuations observed.

\section{Operating Characteristics of the PDCM}

Figure 3 shows operating pressure as a function of flow rate. The graph reflects a spread of operating pressures observed while conducting unsupported coring operations in a number of exploratory holes. Drilling parameters were (1) 1000 to $10,000 \mathrm{lb}$ 


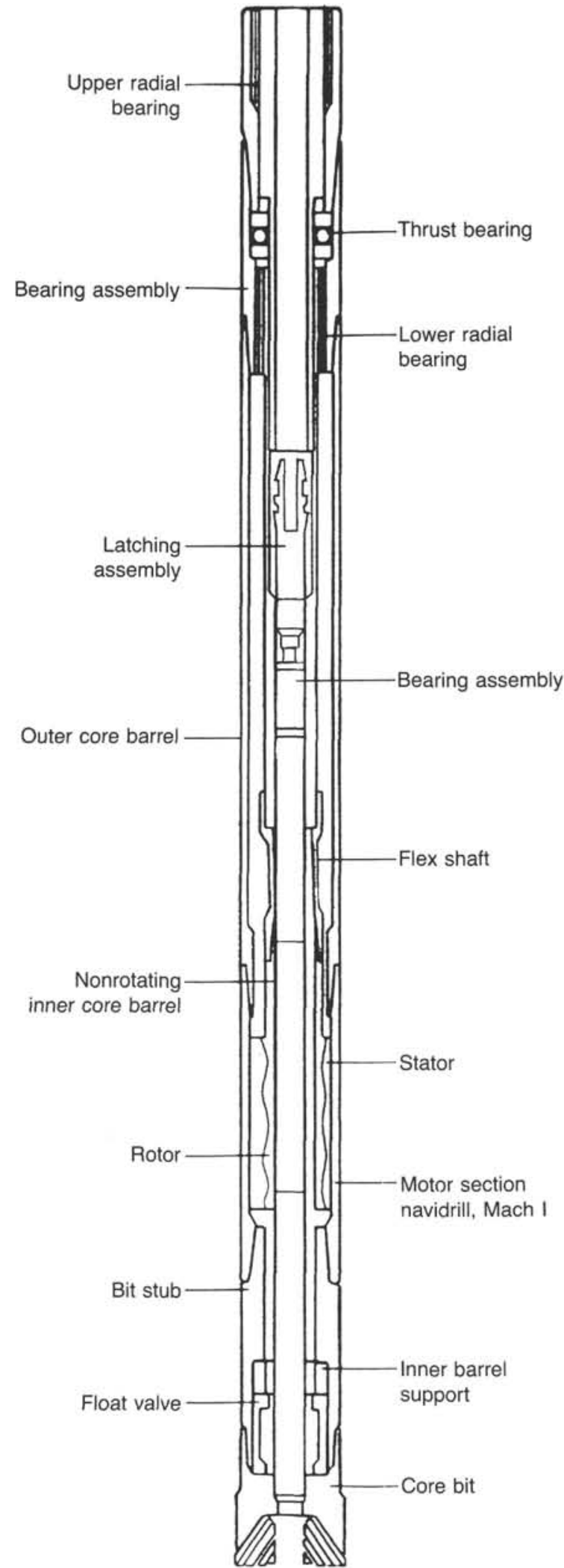

Figure 1. Diagram of the 9.5-in. positive displacement coring motor.

weight on bit, (2) 2.5 - $\mathrm{ft}$ average surface heave (as measured by the heave compensator position indicator), (3) 4.5-s average wave period, and (4) an average water depth of $3800 \mathrm{~m}$. Data were taken while working at Sites 732 through 735 .

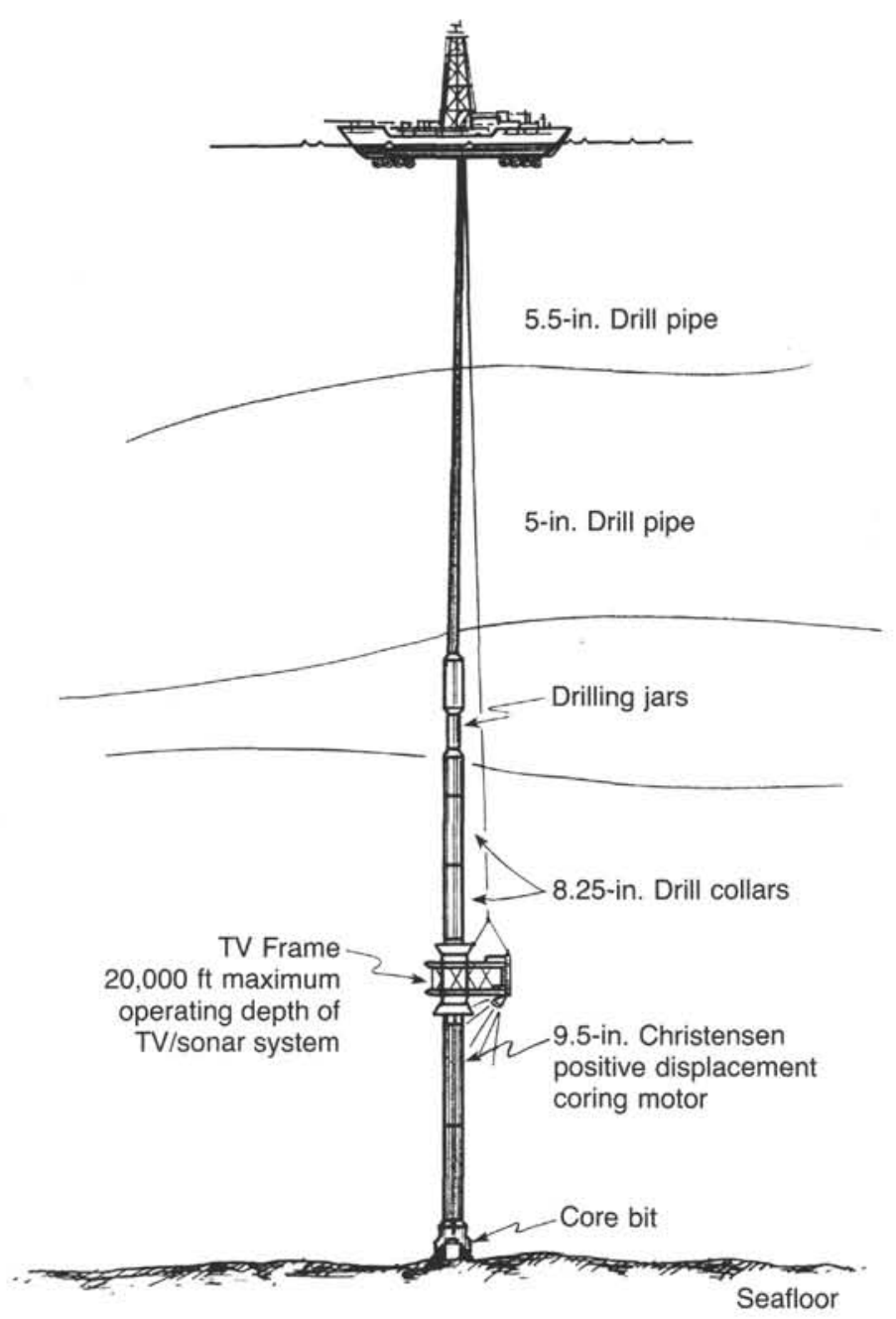

Figure 2. Diagram of the 9.5-in. positive displacement coring motor showing the unsupported bottom-hole assembly.

Figure 4 reflects stall pressures as a function of flow rate. The driller can compare real-time flow rates and operating pressures to both curves to ascertain if the coring motor is rotating properly downhole.

\section{Mechanical Evaluation of the PDCM}

While tripping into Hole $733 \mathrm{~A}$ with the core barrel latched in the coring motor, a piece of rubber from a drill-pipe stabbing guide came loose and fell down the drill pipe. Because fluid was pumped down the pipe to operate the motor, the rubber became lodged between latch fingers. After repeated attempts to engage the latch fingers with the core-barrel pick-up sleeve, the lip of the pick-up sleeve finally caught on the edge of the overshot pulling neck, allowing the core-barrel assembly to be retrieved from the hole. Apparently, this rubber piece had jammed in the latch, caused the latch fingers to collapse, and allowed the core barrel to unseat during coring operations. Seawater was pumped through the motor at a high flow rate to ensure that all restrictions (e.g., rubber, debris, latch, etc.) were cleared. A second core barrel was run in on the wireline and latched into place as coring continued.

During a coring run at Hole 733D, a core-barrel connection failed. The core-barrel-box connection that makes up the bearing assembly failed because of a lack of torsion. This was caused by rocks in the throat of the bit, which induced columnar buckling of the core barrel, as well as torque to the core barrel from the bit and bit sub. The lower end of the core barrel was seized 


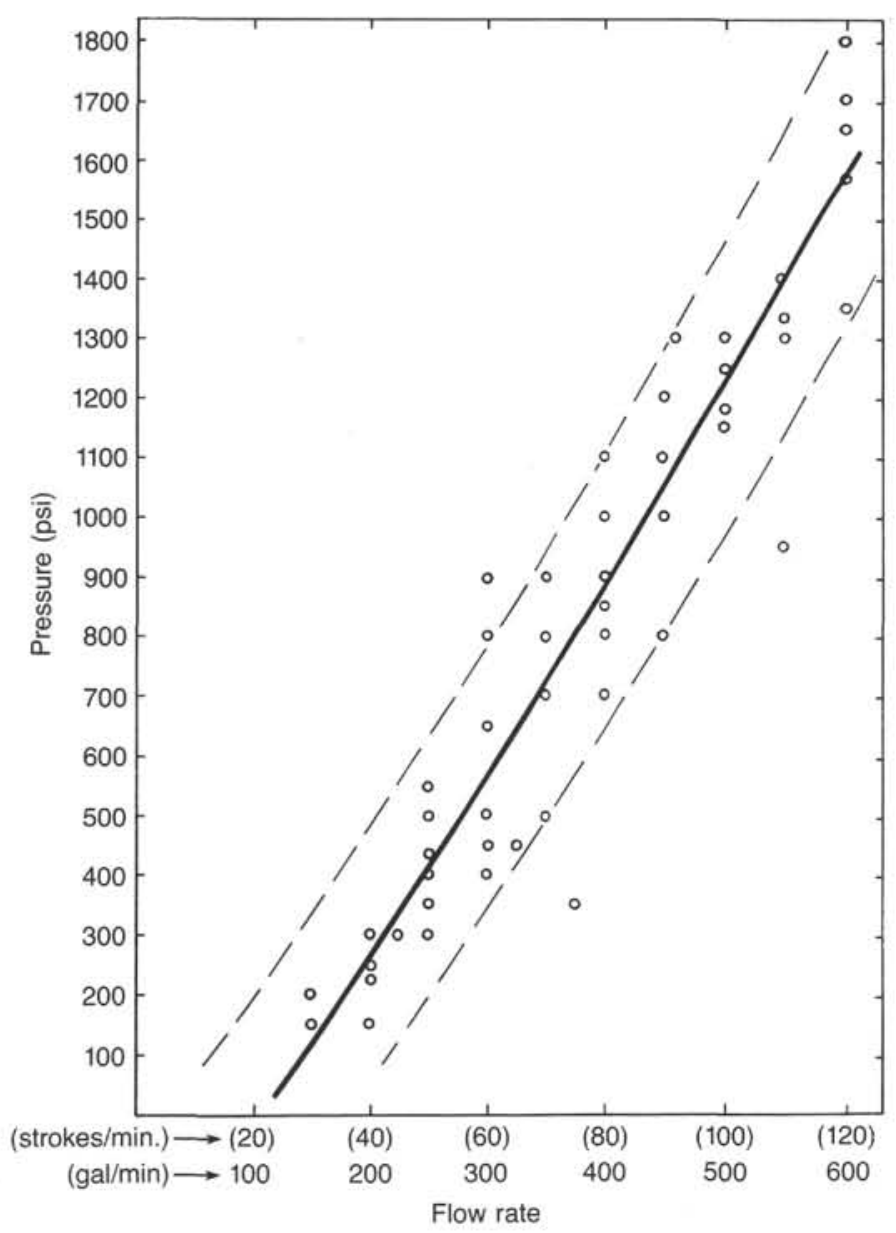

Figure 3. Plot of 9.5-in. Eastman Christensen coring-motor operating pressures as a function of flow rate. Parameters for Sites 732 through 735: weight on bit fluctuation $=1,000-10,000 \mathrm{lb}$; surface heave $=2.5$ $\mathrm{ft}$; heave period $=4.5$; average water depth $=3800 \mathrm{~m}$. Dashed lines $=$ operating limits; dots = data points; solid lines = best-fit lines.

and jammed in the throat of the core bit with finely ground cuttings, and required a sledge hammer to remove it. The rotor/ stator and bearing assembly were also full of cuttings. These were removed by circulating seawater through the motor at the surface.

While using the coring motor in Hole $734 \mathrm{~A}$, we again encountered difficulty when retrieving the core barrel. It took several attempts to retrieve the core barrel successfully. Once the core barrel was at the surface, we found that it was missing two latch fingers. Presumably, the missing latch fingers fell out the end of the bit. A second core barrel was run and latched into place. Before spudding a new hole, we attempted to retrieve the core barrel to check that it was not jammed and that the missing latch fingers were not in it. However, we found that the core barrel had jammed, and after repeated unsuccessful attempts to engage the latch fingers with the pick-up sleeve, we pulled the coring motor out of the hole. We found that the latch was packed, fouled with rust and scale from the drill pipe, and one latch finger was broken. The rust packed between the latch fingers acted as a fulcrum, resulting in the latch-finger pins failing radially outward when the pick-up sleeve engaged the top of the latch assembly. After we removed the core barrel from the coring motor, we found that a latch finger lost during an earlier run was jammed inside the core catcher.

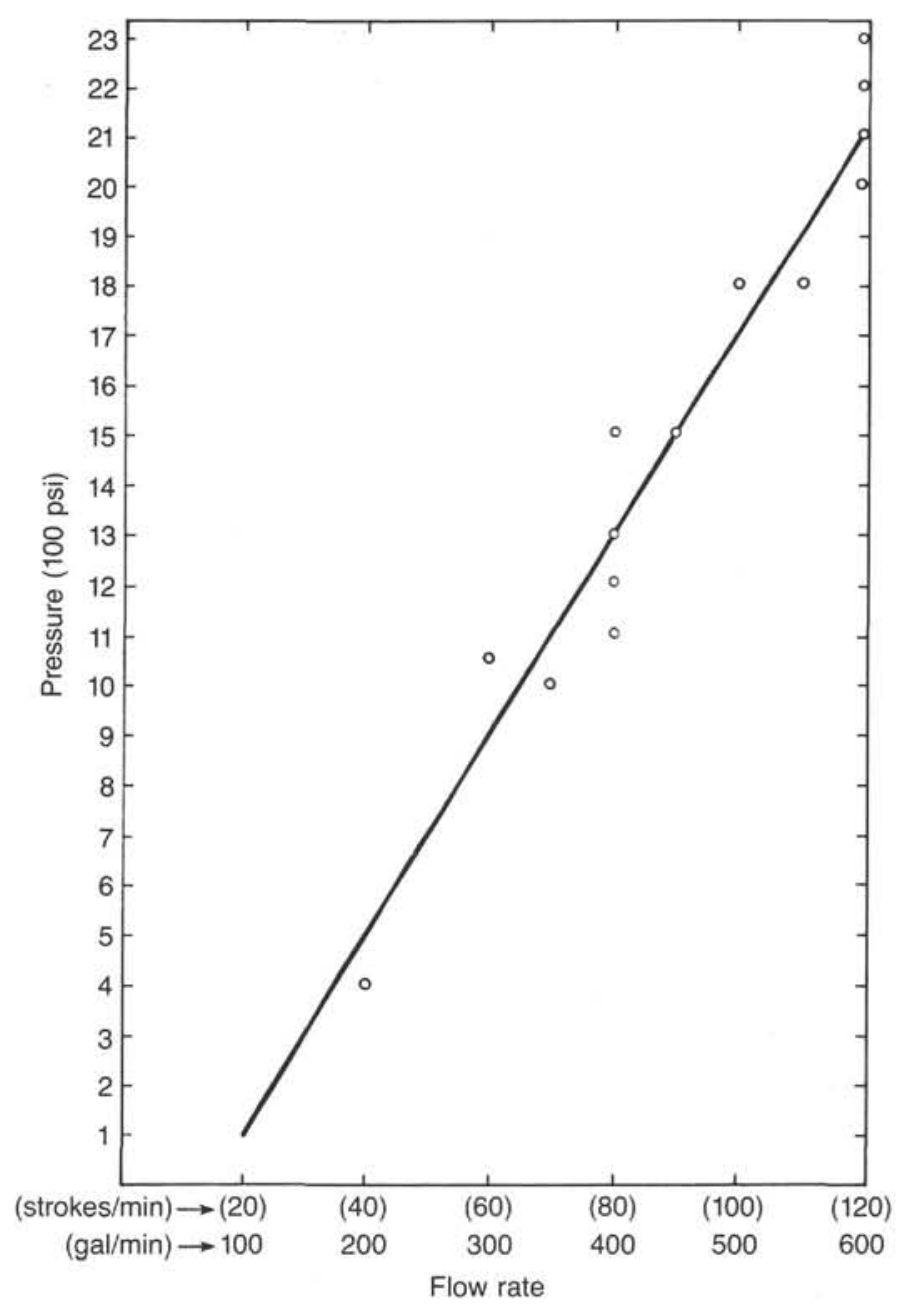

Figure 4. Plot of 9.5-in. Eastman Christensen coring motor stall pressures as a function of flow rate. Parameters for Sites 732 through 735: weight on bit fluctuation $=1,000-10,000 \mathrm{lb}$; surface heave $=2.5 \mathrm{ft}$; heave period $=4.5$; average water depth $=3800 \mathrm{~m}$. Solid lines $=$ best fit line; dots $=$ data points.

While coring gabbro at Hole $735 \mathrm{~A}$, the pin connection on the bit sub failed. This site was free of sediments, and the walking action and skidding of the bit during the initial spudding showed that the seafloor was very hard. After $11.25 \mathrm{hr}$ of rotation and $7 \mathrm{~m}$ of penetration, the Hycalog pin connection failed, which resulted in loss of the bit. This failure was attributed to (1) bending stresses induced in the bit sub by the unsupported BHA and (2) high cyclic torsional loads induced by repeated stalling of the coring motor, which was associated with heaveinduced fluctuating bit weight. Note that after the pin connection failed, the core-barrel assembly remained intact, even though a significant amount of weight and torque from the coring motor was transmitted into the end of the core barrel that protruded from the end of the bit sub.

PDCMs have proven very effective for spudding into a variety of formations (e.g., gabbro, basalt, hydrothermal black smoker deposits, and peridotite) with an unsupported BHA. Use of the PDCM for unsupported exploratory drilling offers a reliable way to spud holes in all types of oceanic rocks in areas having unusual seafloor relief (e.g., Leg 118, with slopes up to $\left.45^{\circ}\right)$. The limited amount of torque available $(600 \mathrm{ft}-\mathrm{lb})$ and the considerable stability of the BHA provided by not rotating the 
entire drill string from the surface minimizes overloading of the drill assembly during the early phases of unsupported spudding operations. If too much weight is placed on the bit or if the BHA is side loaded, the motor stalls. To reestablish effective rotation of the bit, the BHA must be picked up, thereby removing any undesirable or excessive force. Although progress is slow during unsupported spudding of hard rock (e.g., gabbro), use of a coring motor allows shallow exploratory holes to be established effectively and reliably.

\section{EFFECT OF ENGINEERING DESIGN CHANGES MADE FOR LEG 118}

\section{Bearing Design}

Prior to Leg 118, a new bearing design was incorporated into the coring motor drive subassembly. The Leg 106/109 coring motors used a bearing/housing connection that required a special set of screws and thread-locking compound to lock the thread connections together. The new bearing design used during Leg 118 incorporated a more conventional shoulder connection that allowed higher torques to be used to lock it in place.

The bearing-drive subassembly held up well during the difficult spudding operations encountered during Leg 118. PDCM M148 was rotated downhole for $95 \mathrm{hr}$ and motor M147 was rotated for $49 \mathrm{hr}$ (Fig. 1). Longitudinal bearing play was $0.120 \mathrm{in}$. for motor M148 and 0.107 in. for motor M147. Both motors had 0.0709 in. of bearing play before being run downhole. All coring was performed with the PDCM using an unsupported BHA. Use of unsupported BHAs increases significantly the load on the bearings, compared with loads in conventional drilling. We consider the low amount of observed bearing wear as good. Not only is the new longitudinal bearing design superior from the standpoint of wear, but this design adds considerable strength to the drive subassembly.

We found that the new 15-5 $\mathrm{PH}$ stainless steel latch fingers were much stronger than the cast steel latch fingers used during Legs 106 and 109. All problems with the latch system were associated with debris (e.g., rust, scale, rubber, etc.) and fouling or jamming of latch fingers. Although several latch fingers were lost downhole, the fingers themselves did not fail structurally; the threaded hinge pins holding the latch fingers in the latch body sheared off. The accumulation of rust and scale between the latch fingers resulted in the hinge latch pins overloading and shearing radially outward when the pick-up sleeve engaged the top of the latch fingers. These hinge pins acted as a safety device when the latch fingers became overloaded and prevented severe damage to the internal coupling-bonnet latch groove and landing shoulder.

\section{High-Strength Core Barrels}

New high-strength core barrels, with new tapered thread connections, held up well during difficult drilling conditions. During both Legs 106 and 109, core barrels repeatedly failed. These failures occurred at the surface during handling of the core-barrel assembly on the rig floor, as well as downhole during coring. Failures that occurred at the surface were tensile-bending (impact load) failures, and the downhole failures were torsion-induced failures. The only core-barrel failure during Leg 118 was associated with a core jam, as described earlier. The new core barrels were rugged and withstood repeated redressing on the rig floor, as well as routine handling overhead. The only special precaution we took was to lock the threads with a thread-locking compound to prevent the core barrels from backing off downhole. This also prevented vibration from the motor or torque induced by intermittent contact with the bronze bit-sub support bushings and bit throat. Locking the threads caused no thread-galling problems, unusual wear, or loss of time.

\section{Core-Catcher Design}

The new core-catcher used during Leg 118 performed well. During Legs 106 and 109, the core-catcher body threads backed off on numerous occasions. The PDCM core catchers used during Leg 118 were redesigned to enhance overall strength and to stop the core-catcher threads from backing off downhole. At first, the service connection threads on the core-catcher body were locked with a threading compound, but the fine threads repeatedly galled when re-dressing the core-catcher fingers, so we discontinued this practice. No further problems were encountered. The core-catcher service connection was left-handed and never backed off downhole. The tapered thread core-barrel connection on the upper core-catcher body was routinely locked during each coring run and caused no problems.

\section{Further Recommended Design Modifications}

Development of a latch system that is not susceptible to fouling by debris falling inside the drill string is desirable. If it is impractical to build a new latch because of clearance problems, relocation of the flow ports in the coupling bonnet below the latch assembly would alleviate, or at least minimize, the rust and scale that collects between the latch fingers. Now, flow ports for the motor are located above the latch-head assembly to prevent or minimize washing out any of the latch-head components. Because of the relatively short periods of time the latch assembly is exposed to high flow rates downhole, replacement of latch components as they wear over long periods of time should not be a major operating cost. Consideration should also be given to enhancing the strength of the core-barrel latch system so that this system can be allowed to fall freely downhole.

The original (Legs 106/109) core-barrel latch assembly was not mechanically strong enough to fall freely down the drill pipe. By increasing the interval clearance in the PDCM (Leg 118 design) rotor, core barrels having larger diameter (heavier) could be used. If the core barrel could fall freely down the drill pipe one time, a wireline trip could be eliminated for each core run. Now, we must deliver the core-barrel assembly by wireline, rather than free falling, as is conventionally done with other standard ODP core-barrel assemblies.

The strength of the core-barrel system cannot be enhanced by increasing the size or diameter of the core barrel further because of limited internal clearance of the coring motor. However, it may be metallurgically possible to increase the strength and toughness of the material from which the core barrel and latch assembly are made at a nominal cost.

The failure of the pin connection on the bit sub of motor M148 was attributed to the unusually high bending and torsional stresses associated with unsupported coring operations. To increase the strength of the bit sub, the inside bore diameter of the Hycalog pin connection could possibly be reduced by 0.250 in. This, coupled with increasing the strength and toughness of the bit-sub material, should enhance the strength of the bit sub considerably. However, one then would have to modify the diameter of the float valve to fit into the reduced bore of the bit sub (Fig. 1).

\section{HARD-ROCK GUIDEBASE}

\section{Assembly and Deployment}

Details of the hard-rock guidebase (HRGB) assembly and deployment (Fig. 5) have been described by the Leg 106/109 Shipboard Scientific Party (1988). Additional details are given in the ODP in-house engineering assembly and operations manual. During Leg 118, the HRGB was assembled, deployed through the moon pool, manipulated from vertical to horizon- 


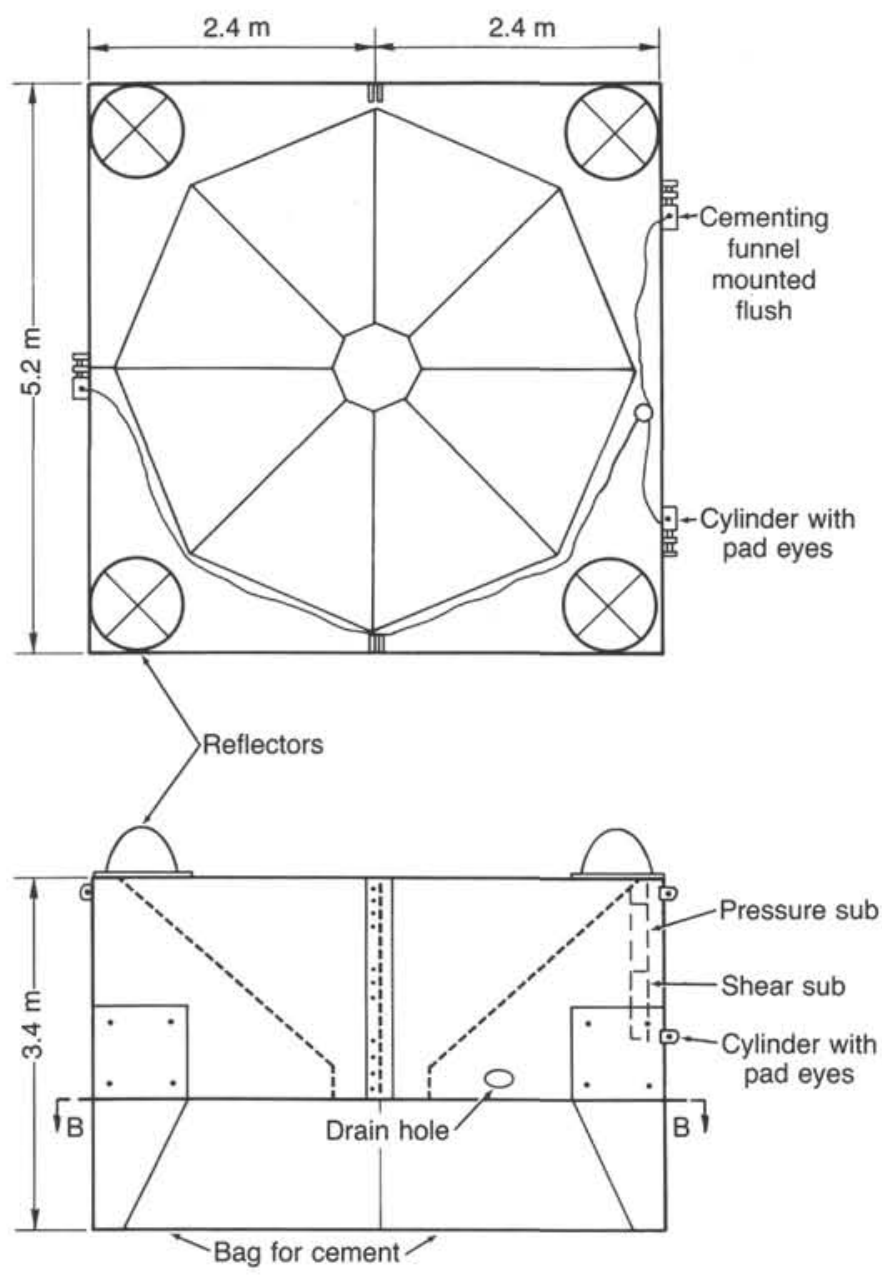

Figure 5. Top and side views of the HRGB. The 18,000-kg guidebase stands on four legs, is $5.2 \mathrm{~m}$ square, and $2.3 \mathrm{~m}$ high. The cone inside the guidebase is $26 \mathrm{ft}(4.9 \mathrm{~m})$ in diameter and $6 \mathrm{ft}$ ( $2.8 \mathrm{~m})$ deep (after Shipboard Scientific Parties, 1988).

tal below the keel, and reassembled, and the rig floor was prepared for tripping the guidebase to the seafloor in a total of $18.75 \mathrm{hr}$ (Figs. 6 and 7). Of this, $5 \mathrm{hr}$ was required to disassemble and reassemble the rotary table plug. The time taken to lower the HRGB $734 \mathrm{~m}$ to the seafloor, to space out the drill pipe in preparation for its landing on the seafloor at Site 735 (Hole 735B), to pick up the cementing head, and to land it on the seafloor required $4.5 \mathrm{hr}$. Actuating the pressure sub, pumping $1864 \mathrm{ft}^{3}$ of $15.5 \mathrm{lb} /$ gal cement, and releasing the kelly hose from the HRGB took $4.75 \mathrm{hr}$. Total time required to assemble, run, release, and cement the HRGB on the seafloor was $28 \mathrm{hr}$. The total time of deployment from the time the first half of the HRGB was picked up and handled through the rig floor, until the first reentry in the HRGB with the unsupported coring motor assembly, was $43.5 \mathrm{hr}$.

No problems were encountered while maneuvering the HRGB from its storage area adjacent to the laboratory stack to the rig floor by crane, when lowering the the HRGB through the moon pool, or when assembling it in the moon pool. During Leg 106, we did encounter difficulty while transferring the HRGB fourpart sling from the crane hook to the rig bails. To alleviate this problem a 50-ft HRGB running cable was attached to the fourpart-sling master link. When the HRGB was moved into position over the rig floor, the other end of the 50 -ft sling was safely attached to the rig bails. The slack in this sling was then taken
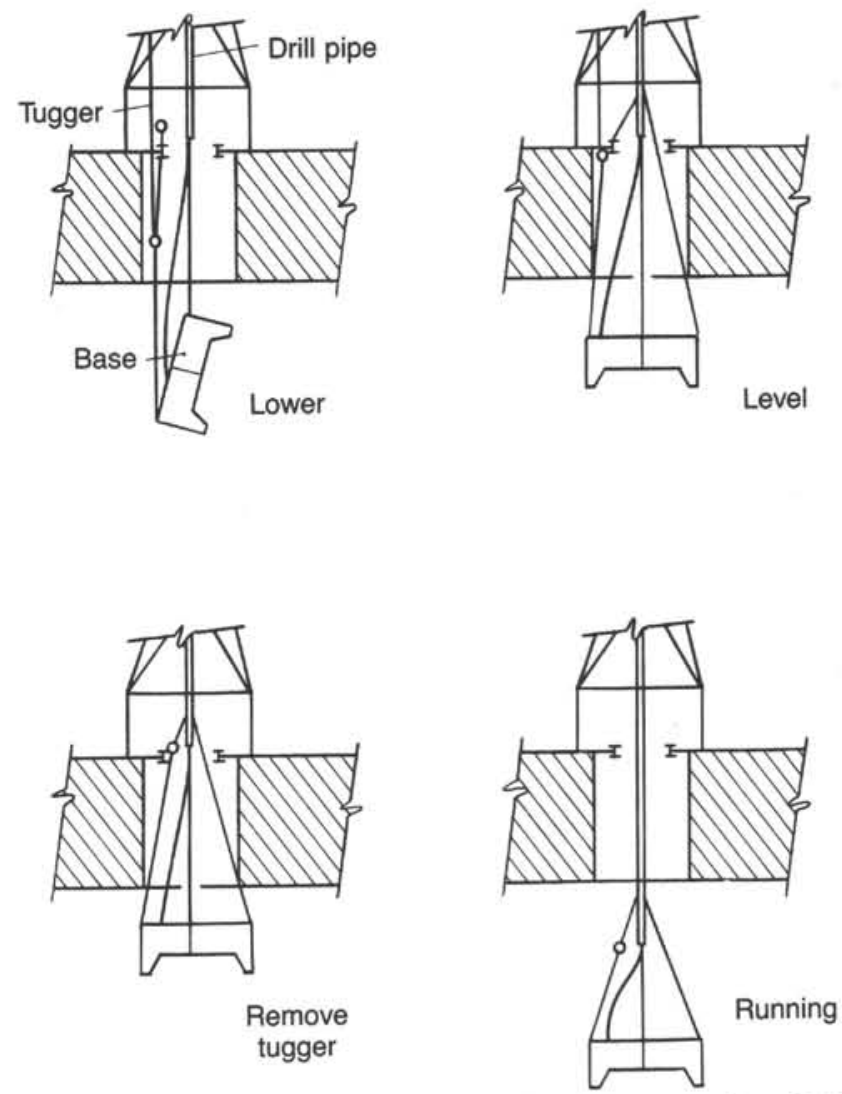

Figure 6. Diagrams showing steps for HRGB deployment (from Shipboard Scientific Parties, 1988).
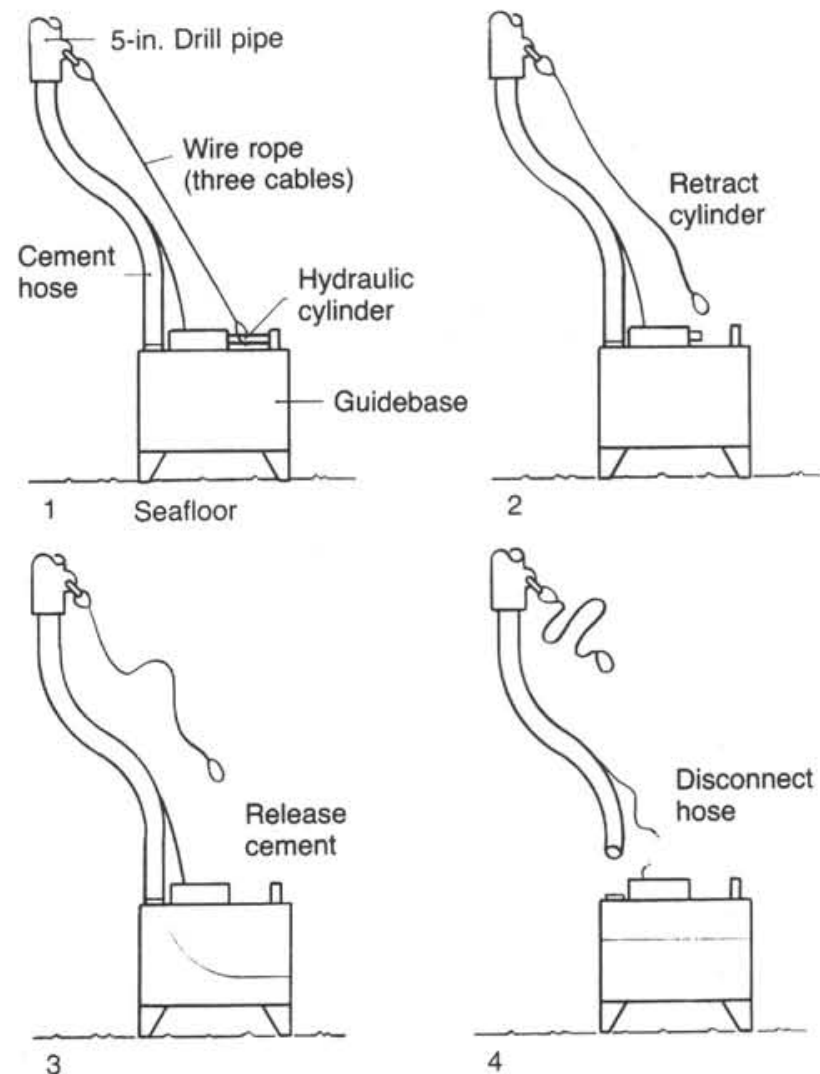

Figure 7. Diagrams showing HRGB landing and cementing sequence (from Shipboard Scientific Parties, 1988). 
out with drawworks, which transferred the load from the crane to the rig bails and allowed the crane hook to be removed easily.

By using a 15 -ft pup joint instead of both 15- and 5-ft pup joints used previously on top of the HRGB running sub, we were able to eliminate the dangerous operation of making up the pup joint connections in the moon pool with rig tongs and tuggers (Fig. 8). The new procedure requires that the 15 - $\mathrm{ft}$ pup joint on top of the HRGB running sub be made up to the HRGB pad-eye running sub while still on the rig floor. Using only the 15 -ft pup joint on top of the HRGB running sub provided adequate clearance below the rig floor for installing the rotary plug with the HRGB running subassembly hung off the moon-pool doors. This modification of the running procedure saved an hour of rig time.

No problems were encountered while tripping the HRGB to the seafloor, but during repositioning, the HRGB 62 -ft running cables became fouled on the corners. The tilt beacon confirmed that these cables were fouled, indicating that the HRGB was hanging at a $20^{\circ}$ angle. The HRGB again was set on the seafloor, which freed the cables, and then was picked up for the last time to adjust the drill-pipe space out and to allow us to attach the cementing head. The tilt beacon then confirmed that the cables were no longer fouled. Later examination of the cable thimbles at the surface confirmed that the cables had been

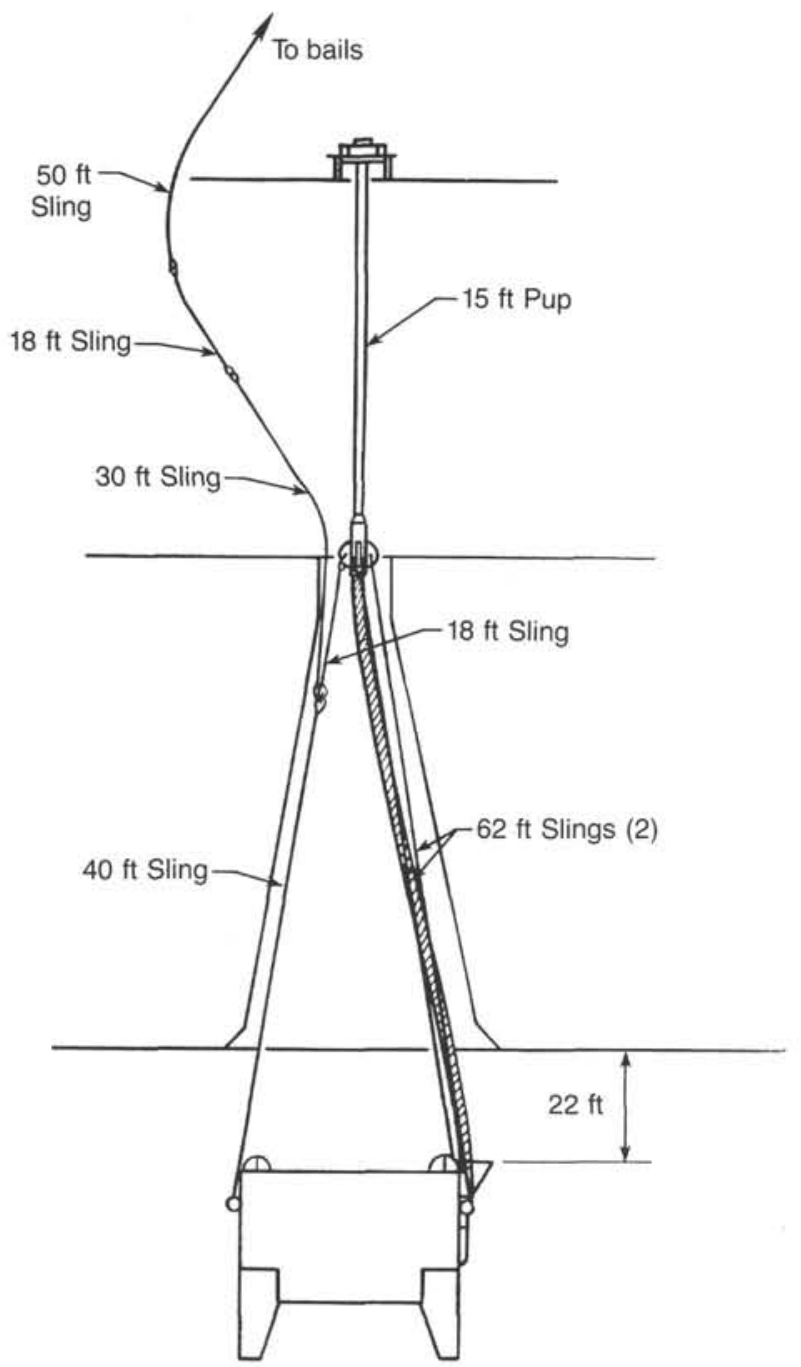

Figure 8. Diagram of the HRGB running configuration with 15 - $\mathrm{ft}$ pup joint. fouled. One thimble was bent at $90^{\circ}$ and the other was bent at approximately $15^{\circ}$.

After completing the spacing out, the HRGB was landed on the seafloor and a Baker pressure sub actuated with the cement pump, releasing the HRGB running cables. The tilt beacon indicated that the HRGB was sitting on the seafloor at a $10^{\circ}$ to $12^{\circ}$ angle. This was later confirmed by viewing the mechanical tilt indicator unit mounted on top of the HRGB with the television/ sonar system. The mechanical tilt indicator was installed as a backup system for the electronic tilt beacon inside the HRGB. Note that the inclination of the 10.5-in.-diameter cored hole near the surface was measured as approximately $6^{\circ}$. The guidebase sitting at a $12^{\circ}$ angle on the seafloor may possibly have contributed to the drilled hole's having a $6^{\circ}$ angle. Possibly, spudding the hole with an unsupported BHA may also have contributed significantly to the hole's $6^{\circ}$ angle.

When pressuring up the drill string to pump the 2.5 -in.-diameter ball out of the pressure subassembly into the HRGB, a significant pressure shock wave was generated as the ball-release mechanism shifted. This occurred when pressure in the drill pipe reached $3500 \mathrm{psi}$. The ball shifted rapidly, decreasing the pressure and creating a shock wave that caused the drill pipe to jump at the surface. We heard a loud noise from the concussion. The impact of the drill pipe jumping and the pressure wave may have caused the kelly hose to whip and, either partially or completely, shear the screws in the backup shear sub release mechanism.

After completing the cable releasing sequence, we pumped $1864 \mathrm{ft}^{3}$ of $15.5 \mathrm{lb} / \mathrm{gal}$ cement into the HRGB. The television/ sonar system indicated that no cement flowed from the HRGB onto the seafloor, which proved that the cement had filled the HRGB. After we finished cementing, we dropped a 2.687-in.-diameter ball to actuate the Brown collet kelly-hose release sub. We tried many times, without success, to pressure actuate and shift the collet release using the cement pumps, but sufficient pressure could not be built up. To release the HRGB, the kelly hose was slowly picked up, but it came loose with 1,000 to $10,000 \mathrm{lb}$ of overpull. We could not ascertain the exact amount of kelly-hose overpull because of the heave-induced fluctuations of the driller's weight indicator. Also, the ship's heaving made it difficult to get a positive indication as to when the screws in the shear sub failed. After tripping the HRGB running assembly to the surface, we found that the ball was seated properly in the collet release sub. We suspect that the three release-cylinder hydraulic hose connections had been severed from the pressure shear sub assembly when the Baker pressure sub was activated. The resulting three 0.5 -in. openings may have prevented the cement pumps from building up pressure on the collet release sub assembly. Use of the mud pumps might have allowed significantly higher flow rates to be generated to overcome the pressure loss associated with the severed hoses and might also have allowed us to activate the collet sub assembly, assuming that the backup shear mechanism was still intact.

While using the television/sonar system to survey the HRGB and the surrounding seafloor, we observed that two of the cement bags were protruding from under the HRGB on the downslope side. This was a good indication that the HRGB had filled with cement. We obtained further confirmation of this when cement was tagged inside the 31-in.-diameter throat of the HRGB with the drilling assembly. In the event that the backup shear sub did release prematurely, we suspect that the pressure-shear sub assembly must have remained inside the HRGB cementing sleeve as a result of friction caused by side loading of the kelly hose, which was coiled on top of the HRGB during cementing.

\section{Evaluation of Mechanical Design}

The new integrally mounted legs saved 2 to $3 \mathrm{hr}$ rig time during assembly and made the assembly much safer than during 
Leg 106, when the legs were mounted separately. During Leg 106 , we had difficulty mounting each of the four HRGB legs separately. Also on Leg 106, we had difficulty attaching the kelly hose to the HRGB because of interference from the externally mounted cement funnel. The flush-mounted cement funnel on the modified guidebase run during Leg 118 provided adequate clearance for easy attachment of the kelly hose to the HRGB in the moon pool.

Why the Brown collet release-shear sub malfunctioned downhole is unclear. However, the backup systems functioned well and allowed us to accomplish required tasks downhole and to successfully deploy the HRGB. Further investigation and technical evaluation will be necessary to determine the optimal pressure-release sub system for deploying the HRGB in the future.

The tilt beacon provided vital information for deploying the HRGB safely at Site 735, where the seafloor is level and boulders are absent. This was clearly evident when the tilt beacon showed that the HRGB cables had become fouled during deployment. The tilt beacon can also indicate any movement of the HRGB that might occur during subsequent reentry and drilling operations. Information relating to changes in inclination of the HRGB during early stages of drilling is vital because it can significantly affect the operation of the secondary reentry cone and the casing run.

Before logging, drill cuttings that were lying on top of the guidebase were washed off by circulating high flow rates with the core bit positioned near the top of the guidebase. Later, when making a subsequent reentry, an obstruction was encountered that we thought was cuttings that may have bridged the hole off. Another possibile source of material causing the bridge in the hole may have been cement filled bags under the guidebase. These bags had been used to provide additional stability for the structure.

\section{Recommended Design Modifications}

Future HRGB designs should call for one-piece construction and a much smaller size than at present. A reduction in size would allow the structure to be run through the moon pool horizontally, alleviating the necessity of maneuvering the HRGB from vertical to horizontal once it is below the keel. The procedure then would be similar to deploying a standard reentry cone. To avoid fouling the HRGB cables while positioning the structure on the seafloor, the running cable release cylinders should be mounted flush with the top surface on the perimeter of the HRGB reentry cone. To compensate for the smaller HRGB structure, externally mounted bags could be attached and filled with cement on the seafloor to provide additional lateral support, depending on the bit confinement requirements.

Overall, the assembly, running, and release procedures for the HRGB are operationally sound. The HRGB was deployed and a hole established in a very short time. Modifications made to the HRGB and its running hardware, together with improvements made to the assembly-handling sequence after Leg 106, have made running the HRGB much safer and also have saved rig time. We gained valuable experience during Leg 118, and several problems were identified that were not observed when the HRGB was first deployed during Leg 106. These engineering observations will benefit the design and deployment of the next generation of guidebases.

\section{DRILLING OPERATIONS IN HOLE 735B}

\section{Unsupported Spudding Operations With Eastman Christensen 9.5-in. PDCMs}

The use of PDCMs for unsupported bare-rock exploratory drilling offers a reliable way to spud holes in various rock types. PDCMs also allow exploratory drilling in steep, rugged terrain, such as the sides of underwater mountains. Although we obtained considerable information during Leg 118 about the drillability of sites using an unsupported coring-motor assembly, core recovery was low. Core recovery can be affected by operational procedures used when spudding a hole with an unsupported drilling assembly; "bit walking" and BHA movement above the seafloor result in break up of core and jamming of the bit throat. In addition, high flow rates $(200-600 \mathrm{gal} / \mathrm{min})$ are required to drive the 9.5 -in. positive displacement motors. In softer or unconsolidated formations, the high flow rates required to drive the coring motor may tend to wash the core away at the bit face. Reducing the flow rate to the coring motor or using a bit sub that diverts a large part of the flow back up the hole above the core bit may improve core recovery in soft formations.

Theoretically, with an unsupported BHA, as the depth of the hole increases, core recovery should increase because more of the BHA is stabilized. In turn, this results in the bits running more smoothly at the seafloor. This can be seen clearly when one examines the bit runs made in Hole 735B, with additional BHA support and bit confinement provided by the HRGB.

The unsupported coring assembly in the HRGB used to spud Hole 735B consisted of a 10.5-in. Rock Bit Industries core bit, an Eastman Christensen 9.5-in. PDCM, a crossover sub, five 8.25 -in. drill collars, another crossover sub, a 7.25-in. drill collar, a crossover sub, and six stands of 5.5-in. drill pipe.

When the HRGB first entered, firm, drillable cement was tagged in its throat. After contacting gabbro, the PDCM ran smoothly and maintained continuous rotation with little or no stalling. However, variations in the weight on bit, which were induced by heave, resulted in repeated torquing and detorquing of the drill string.

Three roller-cone bits $(10.5 \times 2.25$ in. $)$ were run, one of which used thermally stabilized diamond cutters in the throat of the bit to trim the core. The drilling parameters and conditions existing when these bits were run are listed below:

$\begin{array}{ll}\text { Flow rate: } & 400 \mathrm{psi} \\ \text { Indicated surface pressure: } & 400 \mathrm{psi} \\ \text { Weight on bit: } & 8,000-10,000 \mathrm{lb} \\ \text { Ship heave: } & 2-3 \mathrm{ft} \\ \text { Heave period: } & 4-6 \mathrm{~s} \\ \text { String weight with blocks: } & 260,000 \mathrm{lb}\end{array}$

Using PDCMs, a total of $39 \mathrm{~m}$ of hole was drilled in $44.5 \mathrm{hr}$ of rotation. The average penetration rate was $1.4 \mathrm{~m} / \mathrm{hr}$. Individual results of the three bit runs are provided in Table 1.

Core recovery was significantly higher with PDCMs in Hole $735 \mathrm{~B}$ than on those unsupported coring runs made before running the HRGB. The percentage of recovery for bit run 2 is also notably higher than for bit run 1 . The low core recovery for bit run 3 was attributed to the diamond cutters in the throat of the bit dragging on the core, rather than cutting it. At the end of the bit run, the diamond cutters were structurally sound but had

Table 1. Results of three bit runs at Hole 735B.

\begin{tabular}{lccc}
\hline & $\begin{array}{c}\text { Run 1 } \\
\text { (Type C-4) } \\
\text { chisel } \\
\text { (4-cone) }\end{array}$ & $\begin{array}{c}\text { Run 2 } \\
\text { (Type C-7) } \\
\text { conical } \\
\text { (4-cone) }\end{array}$ & $\begin{array}{c}\text { Run 3 } \\
\text { (Type C-4) } \\
\text { hybrid } \\
\text { (3-cone) }\end{array}$ \\
\hline $\begin{array}{l}\text { Hours of rotation: } \\
\text { Meters cored: }\end{array}$ & 12 & 11 & 17.5 \\
Penetration rate $(\mathrm{m} / \mathrm{hr}):$ & 6.5 & 14.5 & 18 \\
Meters recovered: & 0.54 & 1 & 1 \\
Recovery rate $(\%):$ & 2.3 & 6.25 & 5.6 \\
\hline
\end{tabular}


been significantly worn and chipped and were capable of inducing significant drag on the core.

A fourth bit, a hybrid impregnated diamond bit manufactured by Christensen Mining Company, was run with the PDCMs, but no measurable hole was drilled. This bit uses as its primary cutting structure a variable impregnated diamond matrix across the bit crown and a secondary system of thermally stabilized diamond cutters. Drilling parameters for the bit run were as follows: 500 to $600 \mathrm{gal} / \mathrm{min}$, indicated pump pressure of 700 to $1000 \mathrm{psi}$, and weight on bit of 6,000 to $12,000 \mathrm{lb}$. After $2 \mathrm{hr}$ of rotation, the bit was tripped to the surface. A total of $10 \mathrm{~cm}$ of gabbro core was recovered, with this core having an excellent surface finish. Inspection of the bit face revealed that the outside corner of the crown and the throat of the core bit were rounded to a $0.25 \mathrm{in}$. radius. The rounding of the outer- and inner-bit crown surfaces resulted in total destruction of the diamond cutting surfaces in these areas. These areas of the bit became bearing surfaces, rather than cutting surfaces, and prevented the bit from advancing farther into the hole. The face of the bit was in good shape and was not polished. Thermally stabilized diamond cutters showed a $30 \%$ wear. The outer diameter of the bit showed measurable wear. The surface-set natural diamonds on the outer surface of the crown body were still intact. After inspecting the bit crown, we decided that a higher concentration of diamonds on the outer diameter and on the core gauge would be required. Had the bit advanced any significant distance, we believe that core recovery would have been good.

The performance of the PDCMs in Hole 735B was significantly better than for any coring runs made before setting the HRGB. Using PDCMs inside the HRGB with an unsupported BHA to spud a hole was effective and reliable. The hole was established without loss or damage to any BHA components. Although penetration rates were observed to be lower than during subsequent core bit runs made with the 9.875 -in. rotary coring system (RCB), acceptable progress was made and the hole was deepened until it was operationally feasible to switch over to the RCB system.

Although the lower penetration rates associated with PDCMs, as compared to 9.875 -in. rotary core bits, are directly related to the limited bit weight that can be run, several other factors should be considered. These include (1) the 10.5-in.-diameter bit must cut $12 \%$ more hole area than the 9.875 -in. bit, (2) the formation in the upper $50 \mathrm{~m}$ of Hole 735B differed in its physical characteristics from that cored with the 9.875 -in. core bit deeper in the hole (see Site 735 chapter, this volume), and (3) only minimal weight $(5,000-10,000 \mathrm{lb})$ could be run on the bit because of lack of lateral support for the BHA.

\section{Rotary Coring Operations and Hole Statistics}

Hole $735 \mathrm{~B}$ was drilled to a depth of $500 \mathrm{~m}$ in 18 days. This included the time required for pipe trips, reentries, and BHA inspection. Figure 9 shows time vs. depth for Hole 735B during the 18-day drilling period. A total of $434 \mathrm{~m}$ of core was recovered for an average recovery rate of $86.9 \%$ (calculated for all Hole 735B bit runs).

After drilling $39 \mathrm{~m}$ with the PDCM system, the 9.875-in. RCB system was deployed, and the hole extended by another $461 \mathrm{~m}$ in $214 \mathrm{hr}$ of rotation to a total depth of $500 \mathrm{mbsf}$. A total of $420 \mathrm{~m}$ of core was recovered for an average recovery rate of $91 \%$ for the nine RCB runs.

The high recovery rate for the RCB is attributed to the massive crystalline nature of gabbro, which lends itself to being cored effectively with a roller-cone-type core bit. Mylonitized zones in the gabbro (i.e., areas having undergone high-temperature deformation, creating fine anisotropic grain structures), however, make the rock very tough. Gabbro has a considerably higher compressive strength than that of granite or basalt. Esti-

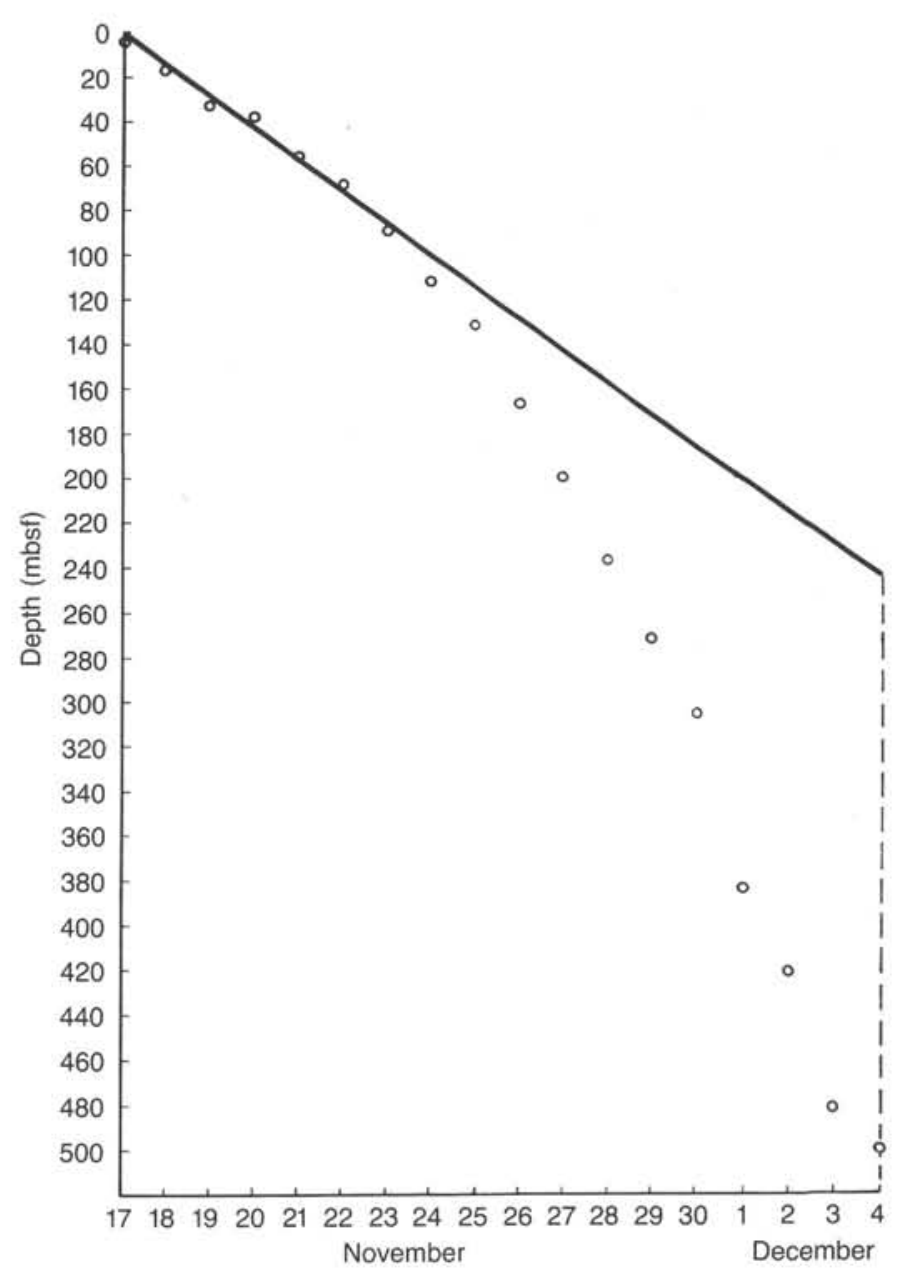

Figure 9. Plot of coring time vs. depth for Hole 735B. Solid line = projected depth at the end of 18 days of drilling; dots = realized depths.

mated compressive strengths for the gabbro drilled in Hole 735B range from 40,000 to 50,000 psi for fresh rock (coarse isotropic grain structure), and $100,000 \mathrm{psi}$ for material that has undergone significant mylonitization.

Drilling parameters for the 9.875 -in. roller-cone bits were as follows:

$\begin{array}{ll}\text { Rotating speed: } & 60 \mathrm{rpm} \\ \text { Average hours of rotation: } & 24.75 \\ \text { Weight on bit: } & 15,000 \mathrm{lb} \\ \text { Flow rate: } & 325 \mathrm{gal} / \mathrm{min} \\ \text { Average penetration per bit: } & 50 \mathrm{~m}\end{array}$

Table 2 summarizes all core bit runs made in Hole 735B (9.5in. PDCMs and the 9.875 -in. RCB systems driven with the top drive). Table 2 shows that core recovery was much higher for the 9.875-in. RCB system than for the 9.5-in. PDCM system. The lower recovery rate associated with the PDCM system was attributed to the following:

1. Most PDCM bit runs were conducted using an unsupported BHA. The BHA's lack of stability above the seafloor produces undesirable bit motion in the bottom of the hole, which breaks up the core as it enters the throat of the bit and causes core jamming. This effect is reduced as the hole is advanced and the BHA is increasingly supported by the surrounding hole. 
Table 2. Core bit statistics for bit runs made in Hole 735B.

\begin{tabular}{|c|c|c|c|c|c|c|c|c|}
\hline $\begin{array}{l}\text { Bit } \\
\text { no. }\end{array}$ & Bit type & $\begin{array}{c}\text { Serial } \\
\text { number }\end{array}$ & $\begin{array}{l}\text { Rotating } \\
\text { hours }\end{array}$ & $\begin{array}{l}\text { Penetration } \\
\text { (m) }\end{array}$ & $\begin{array}{l}\text { Total } \\
\text { depth } \\
\text { (mbsf) }\end{array}$ & $\begin{array}{l}\text { Length } \\
\text { recovered } \\
\text { (m) }\end{array}$ & $\begin{array}{c}\text { Recovery } \\
(\%)\end{array}$ & $\begin{array}{l}\text { Penetration } \\
\text { rate } \\
(\mathrm{m} / \mathrm{hr})\end{array}$ \\
\hline $1-\mathrm{A}$ & $\begin{array}{l}\text { RBI } 10.5-\times 2.25 \text {-in. } \\
\text { four-cone } C 4\end{array}$ & AW693 & 12 & 6.5 & 6.5 & 2.3 & 35.4 & 0.54 \\
\hline $3-\mathrm{C}$ & $\begin{array}{l}\text { RBI } 10.5-\times 2.20 \text {-in. } \\
\text { three-cone } \mathrm{C} 4 \text { hybrid }\end{array}$ & AW797 & 17.5 & 18.2 & 39.0 & 5.56 & 30.6 & 1.04 \\
\hline 4-D & $\begin{array}{l}\text { Christensen } 10.5-\times 2.25 \text {-in. } \\
\text { impregnated diamond hybrid }\end{array}$ & $7 S 6749$ & 2 & 0.2 & 39.2 & 0.08 & 40 & 0.1 \\
\hline \multicolumn{9}{|c|}{ Bit runs made with conventional $9-7 / 8$-in. rotary core-barrel system driven by top drive } \\
\hline 7-G & $\begin{array}{l}\text { RBI } 9.875-\times 2.312 \text {-in. } \\
\text { four-cone } \mathrm{C} 7\end{array}$ & AV721 & 19 & 25.5 & 94.3 & 14.84 & 58.2 & 1.34 \\
\hline 8-H & $\begin{array}{l}\text { RBI } 9.875-\times 2.312 \text {-in. } \\
\text { four-cone } \mathrm{C} 7\end{array}$ & AW089 & 24.75 & 37.75 & 132.1 & 33.4 & 88.5 & 1.53 \\
\hline 9-I & $\begin{array}{l}\text { RBI } 9.875-\times 2.312 \text {-in. } \\
\text { four-cone } \mathrm{C} 7\end{array}$ & AV722 & 24 & 39.5 & 171.1 & 36.7 & 93.0 & 1.65 \\
\hline $10-\mathrm{J}$ & $\begin{array}{l}\text { RBI } 9.875-\times 2.312 \text {-in. } \\
\text { four-cone C7 }\end{array}$ & AV720 & 26.75 & 67 & 238.1 & 64.48 & 96.2 & 2.51 \\
\hline $11-\mathrm{K}$ & $\begin{array}{l}\text { RBI 9.875- } \times 2.312 \text {-in. } \\
\text { four-cone } C 7\end{array}$ & AW088 & 29.5 & 67.5 & 305.1 & 64.87 & 96.1 & 2.29 \\
\hline $12-\mathrm{L}$ & $\begin{array}{l}\text { RBI } 9.875-\times 2.312 \text {-in. } \\
\text { four-cone C57 }\end{array}$ & AW764 & 29.5 & 109 & 413.1 & 102.36 & 94.0 & 3.69 \\
\hline
\end{tabular}

2. The intermittent torque and rotation of the PDCM and the PDCM bit tends to break up the core as it enters the throat of the bit. This contrasts with the RCB system driven with top drive, which produces constant torque and bit rotation.

3. The limited weight on bit and reduced flow rates available when using PDCMs with an unsupported BHA result in lower penetration rates, which also may contribute to core jamming problems (i.e., the core has more chances to jam in the core guide because it remains in the bit throat longer before entering the core guide.)

As the hole advanced, penetration rate increased (see Fig. 10), primarily as a function of decreasing degree of mylonitization of the gabbro being drilled. However, a secondary factor contributing to increased penetration rate was an increase in weight on bit from 15,000 to $23,000 \mathrm{lb}$. In deeper sections of the hole, where penetration rates were $3.7 \mathrm{~m} / \mathrm{hr}$ (Fig. 10), the high core recovery and good penetration rates were attributed to (1) the massive nature of the gabbro being cored, (2) excellent hole stability (lack of hole break outs and rubble infill), and (3) the effective removal of drill cuttings.

\section{Evaluation of Core Bit Performance}

The 9.875-in. core bits run in Hole 735B were either Type 7 or Type 57 conical inserts. The Type 7 insert is a medium-length conical insert and the Type 57 is a medium-length, multiangled (double) conical insert. Although higher penetration rates were observed with the Type 57 cutting structure, no major difference was noted between the performances of the two cutting structures downhole. The high penetration rates observed with the Type 57 cutting stucture were attributed to an increase in bit weight and the massive nature of the gabbro encountered in the deep sections of the hole where the Type 57 core bits were run (see Fig. 10 and Table 2). The main wear was on the nose inserts, and no discernible wear was noted on the middle or heel rows of cone inserts.
Bearing wear was monitored closely during all core bit runs conducted in Hole 735B. During Legs 106, 109, and 111, cones were lost off bits in as little as $6 \mathrm{hr}$ of rotation, when driven with a downhole motor running at $120 \mathrm{rpm}$ and with $5000 \mathrm{lb}$ of weight. Cones also have been lost off bits that were rotated conventionally, with the top drive at $60 \mathrm{rpm}$ and with $35,000 \mathrm{lb}$ of weight on bit. The bearings of all bits pulled out of Hole 735B were typically graded as $20 \%$ to $50 \%$ worn. The current ODP four-cone bit design is reliable up to a maximum of 30,000 to $35,000 \mathrm{lb}$ of weight on bit, depending on hole conditions and how much the ship heaves.

We saw that the lower portion of the stabilizer pads on the bits, facing the bottom of the hole, was repeatedly worn 0.0625 to 0.125 in. under the original wear-pad diameter. Typically, the wear band was 1 in. wide. We found that many of the bits with this wear characteristic were in gauge, or only slightly below gauge. These wear pads are typically 0.03125 to 0.0625 in. below hole gauge when bits are new. Because the hole was unusually clean and the wear point localized, we did not attribute wear on the stabilizer pads to rubble, but rather to the cone legs flexing elastically, which caused the cones to pinch in, thus cutting a smaller hole. Deformation of the legs could cause the cones to skid or skew in the bottom of the hole. The change in the loading angle of the bearing may cause accelerated bearing wear. To substantiate this theory further, the last bit run in Hole $735 \mathrm{~B}$ had a weld failure on one of the cone legs, apparently the result of cyclic flexure stress, possibly induced by the cone leg deforming elastically. The weld crack widened $60 \%$ to $70 \%$ around the entire perimeter of the weld area of the cone segment. The extent of this weld failure allowed us to knock the cone segment out of the bit body with a sledge hammer.

With respect to the design of future bits, the option to run more weight on bit is operationally desirable. The weight on bit that works well for a particular hole and a specific set of operating circumstances may not work well at a different drill site. Further testing and observation will be necessary to confirm 


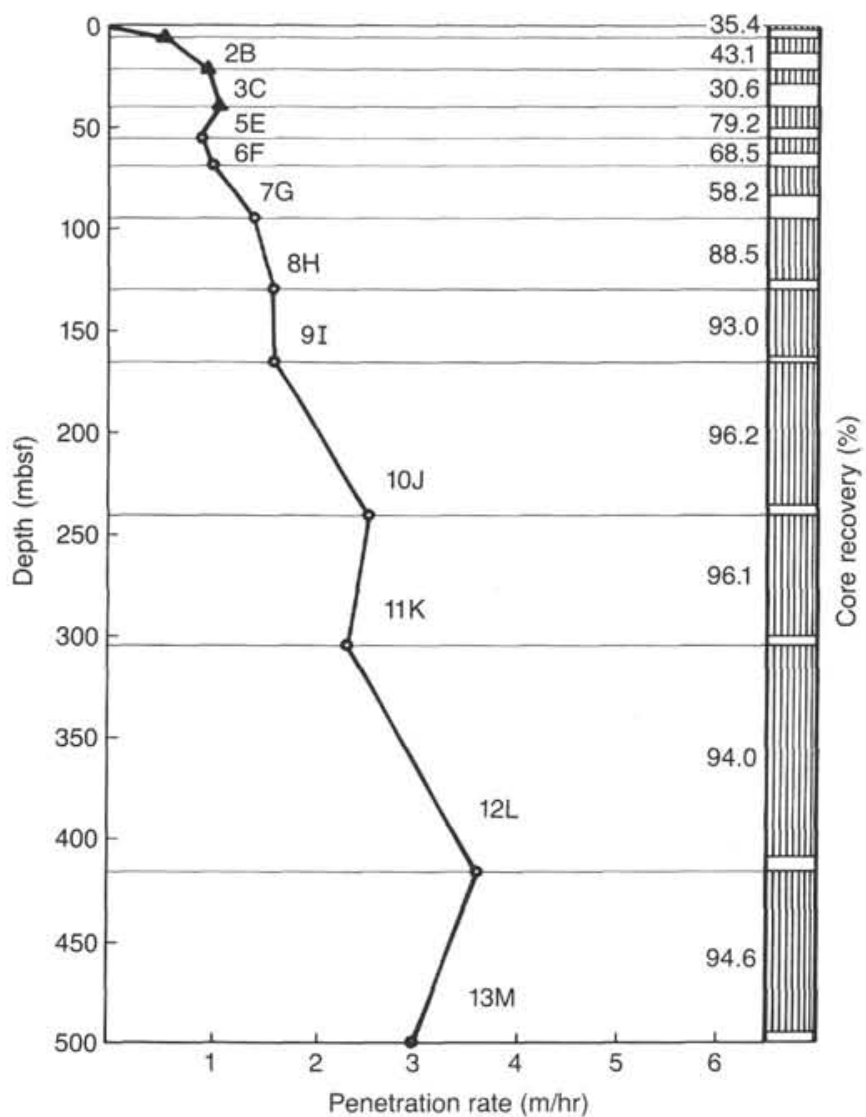

Figure 10. Plot of 9.875-in. core bits run in Hole 735B using type C7 and C57 cutting structure at $60 \mathrm{rpm}, 23,000 \mathrm{lb}$ WOB, and $325 \mathrm{gal} / \mathrm{min}$ vs. penetration rate. Triangles represent $10.5 \times 2.25 \mathrm{in}$. PDCM coring bit runs; circles indicate $9.875 \times 2.25$ in. $\mathrm{RCB}$ bit runs. $2 \mathrm{~B}, 2 \mathrm{C}$, etc. $=$ bit numbers (see Table 2).

that bit legs do flex. By mounting strain gauges on the bit cone legs and by applying gradually increasing loads to a bit (up to $70,000 \mathrm{lb}$ ), it may be possible to determine whether and to what extent the legs are flexing. Depending on the outcome of testing, bit design can be modified as required. It also may be feasible to increase the number of insets in the nose rows to improve wear characteristics of bits in hard-rock formations. One should also consider modifying the lower end of the stabilizer pads to enable the wear-pad edge (oriented down) to trim the hole. This might be accomplished using some type of diamond-hard facing material.

\section{DEPLOYMENT OF THE NAVIDRILL}

\section{Assembly}

The upper, middle, and lower sections of the navidrill coring system (NCB) were assembled and readied for use during Leg 118 (Fig. 11). The navidrill is run in on the wireline or allowed to fall freely down the drill pipe and landed in the BHA (Fig. 12). A flow rate is established (approximately $30 \mathrm{gal} / \mathrm{min}$ ) down the drill pipe that unlatches the NCB assembly, allowing it to enter the open hole. This flow rate is increased to 80 to $120 \mathrm{gal} /$ min, which rotates the drill motor. This in turn rotates the corebarrel assembly (Fig. 13). Attached to the core barrel is a diamond coring assembly (3.75-in. outside diameter $\times 2.25$-in. inside diameter). As the core barrel advances in the open hole (up

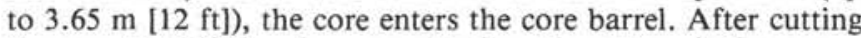
the core, the NCB coring assembly is retrieved by wireline, com-

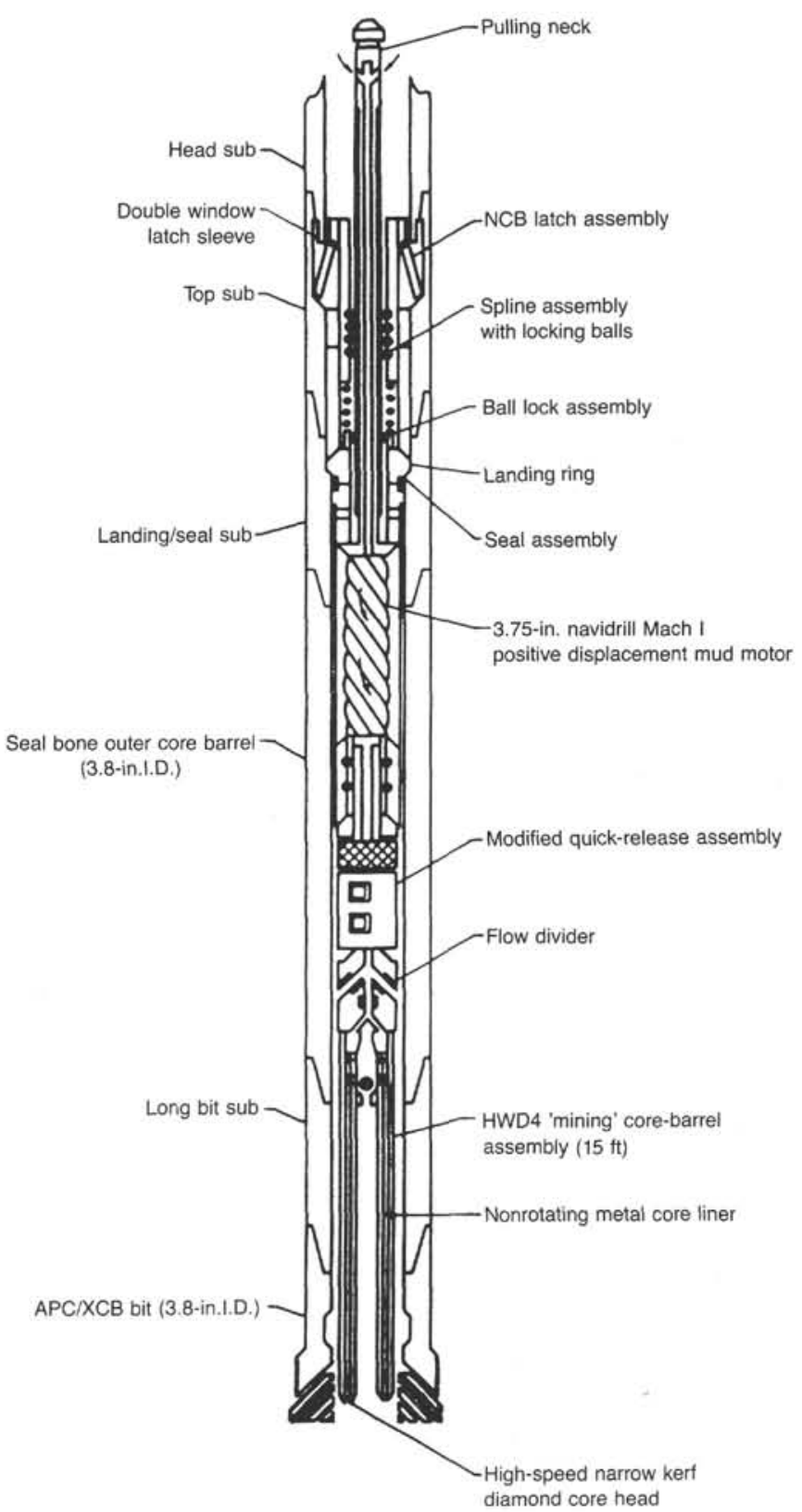

Figure 11. Diagram of the 3.75-in. navidrill core barrel.

pleting the navidrill coring sequence. Before Leg 118, the navidrill coring system $(\mathrm{NCB})$ was redesigned and new parts were manufactured in Celle, West Germany, by Eastman Christensen Co. The NCB was then tested at the Institute of Petroleum Engineering (ITE) in Clausthal, West Germany. The NCB was tested and evaluated under actual downhole drilling conditions at ITE with good results.

For Leg 118, the upper section was assembled with a new steel male spline. The NCB version tested during Leg $114 \mathrm{had}$ a brass male spline. The failure of this spline during Leg 114 caused us to build a new high-strength steel male spline for Leg 118. These new male splines were coated with Teflon to reduce the friction between the male and female splines sliding on contact surfaces. Removal of the Teflon coating after testing alleviated the clearance problem that prevented installation of the female spline onto the male spline in Germany. The female spline 


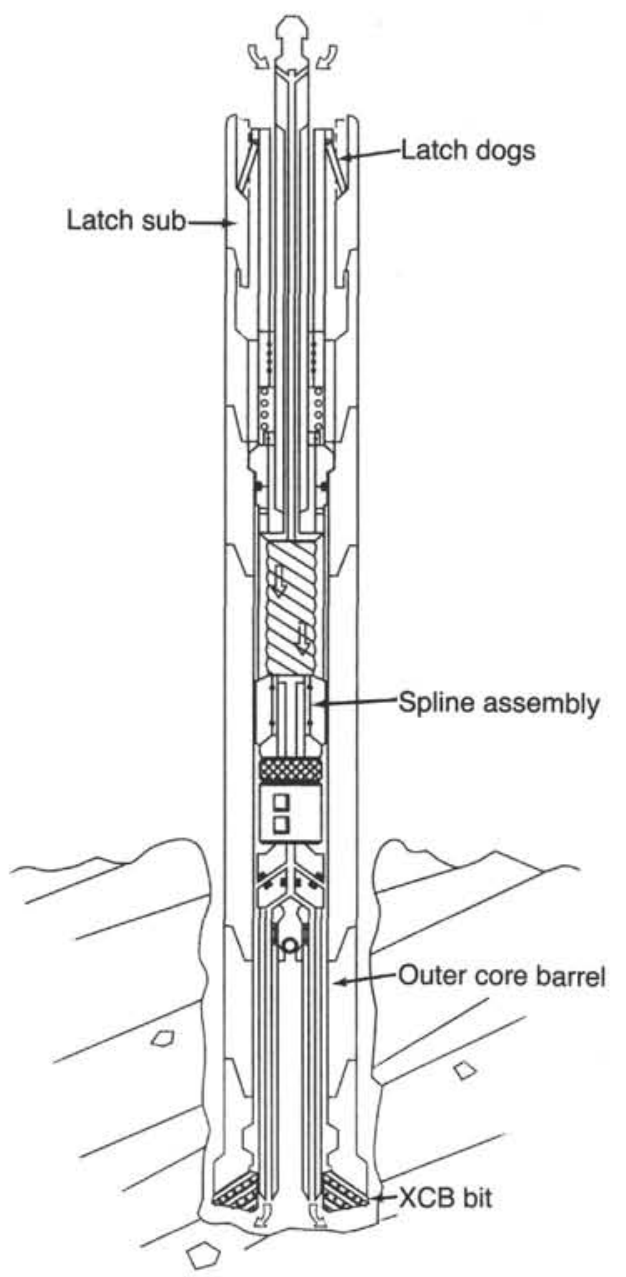

Figure 12. Diagram showing operational sequence when deploying the navidrill core barrel. Sequence of events is as follows: (1) Land NCB in outer core-barrel assembly; (2) Place XCB bit on bottom and circulate to determine beginning flow and pressure parameters; (3) Lock spline assembly in up position and engage NCB latch deep in latch sub.

slid freely over the entire length of the spline before installation of the thruster adapter. A new quick-release assembly compatible with the Leg 118 flow divider was used. Several earlier versions of the NCB were deployed during Legs 104 and 114. After each deployment, we modified the flow diverter and latch system in an effort to improve performance of the tool.

The lower core-barrel section was assembled with an antijamming system, a short breakoff sub, and a slip-type core catcher. The flow divider was jetted with two 0.344 - and one 20/ 32 -in. nozzles. The thruster nozzle was jetted with both 0.344 and 10/32-in. nozzles. We selected this nozzle configuration to provide adequate thrust for drilling the rock type encountered in Hole 735B, where the first test was conducted.

We used a Christensen hard-formation impregnated bit. This bit had a square crown and was classified as a soft matrix bit. A soft matrix allows the diamonds on the bit to be abraded at a moderate rate, thereby exposing new, sharp diamonds to continue aggressively cutting the hard, abrasive gabbro. Because of the excellent core recovery we experienced when using the conventional RCB system and because no cores jammed, we did not run a core liner.

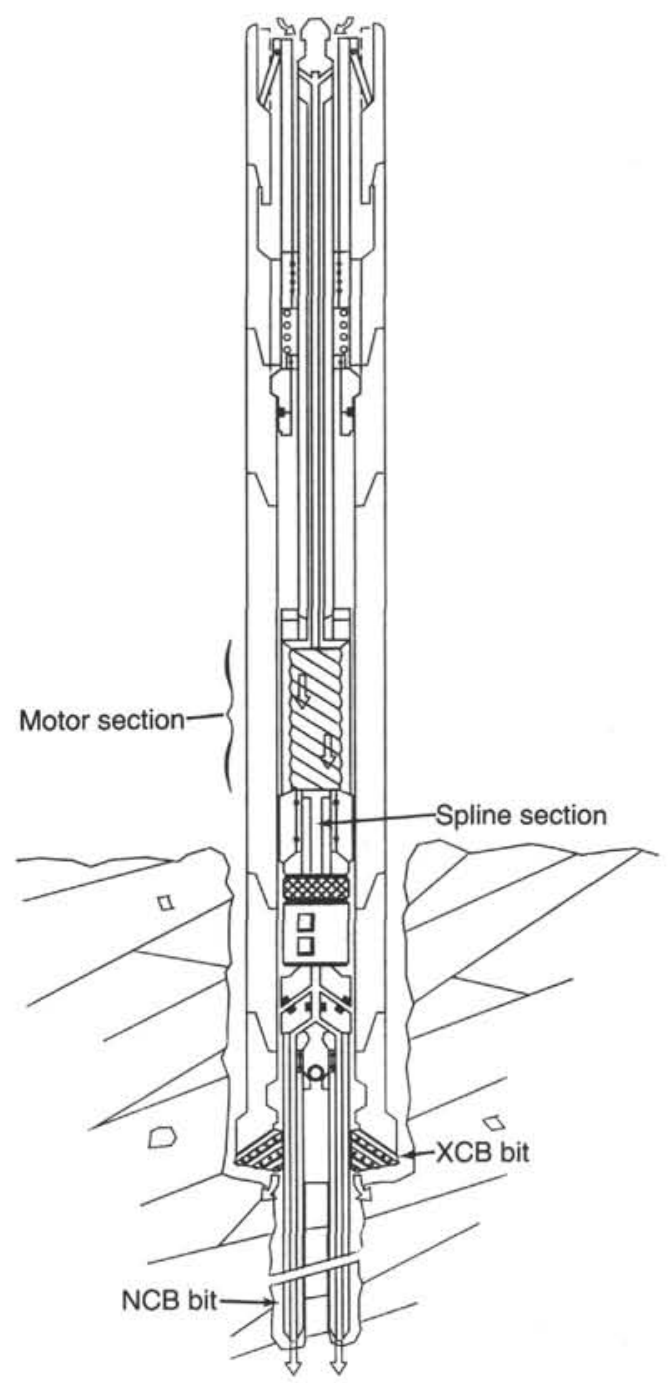

Figure 13. Diagram of the navidrill core-barrel operational sequence when coring ahead. Sequence of events: (1) Using circulation pressure, disengage locking balls on spline assembly; (2) Increase flow rate to produce desired WOB; (3) Monitor flow and pressure parameters while coring. A constant high pressure probably indicates motor stall. A constant low pressure probably indicates core block; (4) NCB system penetrates ahead of XCB bit as coring begins.

\section{Navidrill Deck Test}

A standard advanced piston corer/extended core-barrel (APC/ $\mathrm{XCB}$ ) assembly with one 8.24 -in. drill collar was made up and hung off the rig floor. A standard long top sub was run instead of the special top subs having reduced bore that are manufactured in Germany. This was done in case we had to recover a sample using the APC should adequate sediment cover be encountered in subsequent navidrill coring operations outside Hole 735B.

First, we conducted a space-out test, which is a dimensional check to insure that the NCB coring assembly fits properly in the outer core-barrel assembly. Then, the NCB assembly was run into the outer core-barrel assembly and landed in place with the new Christensen delivery system. The space-out measurement for the NCB core was 2.406 in., not the required 3.031 in. This 0.625 -in. error was attributed to tolerance problems with 
the length of the outer core-barrel assembly. We initially thought that the 0.6250 -in. error might indicate that the NCB coring assembly was not landed properly in the outer core-barrel assembly. We selected a natural diamond bit for deck drilling because the cement test block had not cured fully.

We placed the cement test block under the NCB BHA and applied approximately $6000 \mathrm{lb}$ of weight. We established a flow rate of $30 \mathrm{gal} / \mathrm{min}$, with no pressure indication on the rig-floor gauge. We increased the flow rate to $40 \mathrm{gal} / \mathrm{min}$, at which time the bit began to rotate and to extend out as the NCB unlatched. At $45 \mathrm{gal} / \mathrm{min}$, we noted a pressure of $350 \mathrm{psi}$. We then increased the flow rate to $50 \mathrm{gal} / \mathrm{min}$; visual inspection confirmed that the NCB had unlatched and was coring the cement test block. Pressure increased continually at a moderate rate during the $3 \mathrm{~min}$ it took to cut through the cement. The indicated surface pressure at this point was $2500 \mathrm{psi}$ and it was still increasing as the bit broke through the bottom of the cement block. We had to stop rotation before the pressure stabilized because of the short time it took us to cut through the test block.

The NCB was pulled from the outer core barrel and laid out. We encountered difficulty when rescoping and relatching the thruster adapter-ball latch system. Some evidence of galling on the male spline could be seen, but damage was considered minimal. While relatching this tool, compression in the springs on the female spline was suddenly released, we heard a noise like a gun discharging. The springs may have been compressed almost to their solid height. The dampening cylinder O-ring was checked and found to be in good condition. We redressed the lower corebarrel section with the hard-formation impregnated bit.

We checked the spacing with the new impregnated bit before running the NCB in the hole. We found that instead of passing through the end of the bit, the NCB was resting on top of the $\mathrm{XCB}$ float-valve spacer ring. The spacer ring has a 0.375 -in.-diameter bore, while the outside diameter of the NCB bit is 3.75 in. The square crown on the impregnated bit has a maximum of 0.0625 -in. $\times 45^{\circ}$ chamfer on the edge of the crown. The 0.050 -in. minimal clearance in the spacer ring, coupled with the square crown profile, caused the NCB bit to hang up in the bit sub.

We removed the dummy bit and the spacer ring. This ring bore was machined to $4.05 \mathrm{in}$. and a $30^{\circ}$ chamfer was machined out to $4.3 \mathrm{in}$. We rechecked the space out with the modified spacer ring. The space out measured exactly 3.03125-in., as specified. We removed the NCB from the outer core barrel and relanded it. The space out then was checked again; it again measured 3.03125-in. No problems were encountered with the NCB bit hanging up in the bit throat after the spacer ring was modified. The natural diamond bit used for the cement drilling test had a more rounded crown, which allowed it to guide itself into the spacer ring more easily than the square-crowned NCB design. The 0.625 -in. space-out error noted with the natural diamond bit during the first space-out test was attributed to the tight clearance in the spacer ring, rather than a problem with the dimensions of the APC/XCB outer core-barrel assembly, as we originally thought. Difficulties encountered during earlier legs, such as not being able to establish rotation with the navidrill downhole, may have been associated with the problem of the spacer ring clearance.

\section{Deployment of the Navidrill in Hole 735B}

After completing the deck test, the NCB outer core-barrel system was run to the seafloor. The Eastman Christensen delivery tool was tested with the dummy bit positioned $30 \mathrm{~m}$ above the seafloor before reentering the HRGB. The purpose of the test was to determine whether there would be any problems if the delivery tool prematurely released the NCB, causing the tool to fall freely down the drill pipe. We were confident that the NCB dampening system would decelerate the tool properly when landed. However, because of the significance of Hole 735B, we took extensive precautions to preserve the integrity of the hole. The NCB was run into the hole and released without problems. After we retrieved the NCB assembly with a standard overshot, Hole 735B was reentered and the dummy bit was run to the bottom of the hole.

We had to build a special APC/XCB dummy bit that was compatible with the 9.875-in.-diameter of Hole 735B. Both the $117 / 16$ - and the 10.5-in. APC/XCB bits on board the ship were incompatible with this hole size. The NCB was designed to be deployed during or at the end of an APC/XCB bit run in a single-bit hole. We had to cut a maximum of $5 \mathrm{~m}$ of core with the $\mathrm{NCB}$ in the bottom of the hole. Because we did not have to advance the large bit and the hole was extremely clean, we used a dummy bit that would maintain the proper spacing above the bottom of the hole. The cones and legs of a used 10.5-in. APC/ $\mathrm{XCB}$ bit were removed, and in their places, five landing feet were welded in place. The exact overall height and space-out relationships of an APC/XCB bit were maintained. We had planned to run $25,000 \mathrm{lb}$ of weight on bit. After completing construction of the dummy, we decided that only $15,000 \mathrm{lb}$ should be run on the dummy bit to ensure that the welded feet did not come off and possibly jam the hole. The finished dummy bit had an outside diameter of 9 in.

The dummy bit was positioned in the bottom of the hole with $15,000 \mathrm{lb}$ of weight on bit, and the hole was conditioned. Two 25-bbl, high-viscosity mud sweeps were pumped, separated by a 100 -bbl saltwater sweep. This was followed by a volume of seawater five times the hole volume pumped at $1000 \mathrm{gal} / \mathrm{min}$. After conditioning the hole, we picked up the bit off the bottom and ran the NCB coring assembly in on wireline with the delivery tool. An account of the NCB coring run performed in Hole 735B follows.

Time

Action

1835 Broke circulation, $50 \mathrm{gal} / \mathrm{min}$; no indicated pressure at the surface.

1838 Increased flow rate to $100 \mathrm{gal} / \mathrm{min} ; 700 \mathrm{psi}$ indicated surface pressure; pressure gradually increased.

1840 Increased flow rate to $150 \mathrm{gal} / \mathrm{min}$; indicated surface pressure of $2500 \mathrm{psi} ; 15,000 \mathrm{lb}$ weight on bit. Surface pressure stabilizing. NCB was coring.

1842 Maintained $150 \mathrm{gal} / \mathrm{min} ; 2300 \mathrm{psi}$ surface pressure; $15,000 \mathrm{lb}$ weight on bit.

1845 Increased weight on bit to $20,000 \mathrm{lb}$. Concern that bit may possibly be heaving off the bottom of the hole, as evidenced by the surface pressure fluctuations observed.

1850 With heave compensator, adjusted weight on bit to $10,000-15,000 \mathrm{lb}$.

1855 Sudden increase in pressure to $2800 \mathrm{psi}$.

1900 Suspected motor stall or possibly cut full-length core; pressure increased, caused by thruster nozzle entering choke sub. Adjusted weight on bit to 8,000 to $10,000 \mathrm{lb}$. Pressure decreased to $2500 \mathrm{psi}$.

1905 Maintained $150 \mathrm{gal} / \mathrm{min}$; surface pressure, $2450 \mathrm{psi}$; $12,000 \mathrm{lb}$ weight on bit., Stopped rotation and pulled bit up off the bottom. Had 20,000 lb overpull; possible indication of a core break. Actual coring time, 1840 to $1905 \mathrm{hr}$ (i.e., $25 \mathrm{~min}$ of rotation). 
The dummy bit was pulled up off the bottom, and the NCB coring assembly was retrieved. The upper and middle sections of the NCB were kept together and hung off in the handling shuck. The lower core-barrel section was laid out, and the NCB bit was removed. The core barrel contained $0.7 \mathrm{~m}$ of gabbro, the longest continuous piece of unbroken core recovered from Hole 735B. The bit crown was severely damaged, possibly by (1) a core stub left in the hole from the previous RCB bit run, (2) one or two small pieces of broken core left in the hole, or (3) several carbide buttons lost off the RCB bits. The inside of the bit crown was worn (some beveling) heavily toward the center of the bit, possibly by the core stub. The water courses also were worn away and were plugged. The diamonds on the bit face had not been polished.

We decided to suspend coring operations in Hole 735B in an effort to preserve the integrity of the hole. We were concerned that the core barrel or bit crown might possibly have been left in the hole because of not being able to run an adequate amount of weight on the dummy bit to keep the BHA motionless in the bottom of the hole. Had we been able to cut a second core in Hole 735B, we might have had better results. The improved geometry in the bottom of the hole (absence of RCB core stub) and grinding up of core fragments on the first NCB coring run might have provided considerably better conditions for continued NCB coring.

\section{Unsupported Spud-in Coring Attempt with the NCB, Hole 735C}

After tripping the pipe out of Hole 735B, we planned to run the NCB back in the drill pipe by wireline using the delivery tool and to try to cut a core using an unsupported BHA. We recognized that testing the NCB using an unsupported BHA was not the ideal situation. However, the information that could be gained from such a test would be of great benefit when assessing the capabilities of performing shallow exploratory coring in a manner similar to that done with PDCMs. Another contributing factor in this decision was that there was not enough time to relocate the ship to an area where sediment cover was present.

Had the first unsupported coring attempt been successful, a second coring run would have been made with the unsupported BHA after allowing the NCB system to fall freely to the seafloor. While running the NCB in on the wireline, we saw that the wireline weight indicated that the tool was floating somewhat. This meant that the check ball installed on top of the PDCM was forcing the fluid inside the drill pipe to flow around the NCB assembly and was producing a significant braking effect on the system. We felt this evidence justified our conducting a free-fall test in open water.

Before running the NCB in on the wireline, we encountered significantly more difficulty when relatching the thruster adapterball latch assembly. We had to drop the upper and middle sections of the NCB repeatedly in the handling shuck on a tugger line for the tool to relatch. We noted damage on the spline corners where the balls ride (Fig. 11). Again, after we finally did relatch the NCB as the springs expanded, we heard what sounded like a gunshot.

The NCB was run in on wireline and delivered again without difficulty. The area in the vicinity of the beacon was covered with a thin layer of sediment. The bit was lowered to the bottom and $15,000 \mathrm{lb}$ of weight was placed on it. Sediment cover was no more than $5 \mathrm{~cm}$ thick; we presumed that the underlying rock was gabbro. An account of the unsupported NCB coring run in Hole $735 \mathrm{C}$ is given below.
Time

Action

2315 Tagged the seafloor and applied $15,000 \mathrm{lb}$ of weight to the bit.

2318 Brought flow rate up slowly to $150 \mathrm{gal} / \mathrm{min}$, indicated surface pressure of 2700 psi. Readjusted , pump to $140 \mathrm{gal} / \mathrm{min}$, surface pressure of $2400 \mathrm{psi}$. Observed dummy bit rotating on the bottom and reactive torque in the drill pipe back to the surface. Locked top drive brake to counter reactive torque.

2325 Decreased flow rate to $135 \mathrm{gal} / \mathrm{min}$; surface pressure $2400 \mathrm{psi}$, with occasional spike to $3000 \mathrm{psi}$. Suspected motor stall associated with BHA motion.

2328 Observed bit pumped off bottom and NCB corebarrel bending. Ceased NCB coring immediately and tripped pipe out of hole with the NCB in outer core-barrel assembly.

To free the NCB coring assembly (Fig. 11), we had to cut the core barrel in three places. The core barrel was bent about $1 \mathrm{~m}$ from the NCB bit, and was slightly bent for two-thirds of the entire barrel length. We encountered extreme difficulty when extending the spline out to remove the core barrel. When the core barrel extended out onto the seafloor, significant galling occurred. After removing the lower and upper sections from the outer core barrel, we tried to relatch the thruster adapter-ball latch assembly. After we worked the female spline onto the thruster adapter, the assembly jammed. The ball ports in the female spline were $0.5 \mathrm{in}$. from the ball groove in the thruster adapter when the latch system jammed. We had to cut the landing and dampening sleeves off the female spline to release compression on the balls and thruster adapter shaft. No grit or sand was found inside the system. The springs remained loaded until we cut into the sleeve. Inspection of the male spline revealed significant galling along the corners of the spline where the balls make contact. The female spline would no longer slide along the male spline unless we applied excessive force with tuggers.

\section{Evaluation of Mechanical Design}

The inherent design of the ball-latch groove forced the balls to drag or load up against the thruster adapter and splines. The more load that is applied, the greater the wedging or jamming force generated. By reducing the ball size and modifying the angle of the ball groove, it may be possible to correct these problems. However, alternative latch systems should also be explored. The travel length of the dampening system should be increased from 2 in. to 8 to $12 \mathrm{in}$. This will add a margin for error to the hydraulic system, which now must be finely balanced and has no margin for error. Ideally, the dampening and latching functions should not be separated. If this is not practical, then having adequate distance to perform both functions with some over-traveling built into the dampening system will greatly improve its reliability.

The middle and lower sections of the NCB are mechanically sound. Reducing the number of components to simplify assembly and inventory of parts on the rig should be tried. It might be possible to combine two or more components into a single part. For example, the female quick-release and flow divider could be made as one unit. The number of variable pressure decreases in the NCB hydraulic system should also be reduced. This will benefit the prediction and understanding of downhole operating characteristics of the NCB. 


\section{OBSERVATIONS AND CONCLUSIONS}

1. When the NCB stalls out, the increased pressure was observed to be significantly higher (by up to $25 \%$ ) than theoretical values. This increased pressure can cause the navidrill to scope out ahead of the APC/XCB bit with sufficient force to pick the BHA off the bottom when light bit weights are run (either inside a hole or during an unsupported spudding attempt).

2. Most likely, the NCB pulled the bit off the bottom in both Holes 735B and 735C. We deduced this from similar surfacepump pressure readings that were observed during the two NCB coring runs and by examining the core recovered from Hole $735 \mathrm{~B}$, which is slightly "S"-shaped. The gauge hole prevented the core barrel from being bent when the core barrel stroked out for short periods of time.

3. As shown by both the reactive torque in the drill pipe (observed at the surface) and the thrust exerted against the BHA, the navidrill system, when seated properly, is capable of generating more than ample torque for coring rock types such as gabbro.

4. Based on the significant amount of reactive torque and thrust observed during the unsupported spudding attempt, the use of a high-speed, low-torque motor and/or larger size nozzle should be considered.

5. To prevent the NCB from pulling the bit off the bottom, more than $20,000 \mathrm{lb}$ of weight should be maintained on the bit, then adjusted to higher levels as heaving of the ship dictates.

6. To further promote BHA stability during future deployment of the NCB, both near-bit and string stabilizers should be considered, especially in the 11.4375-in.-diameter holes.

7. The navidrill coring system has been shown to be capable of cutting a high-quality undisturbed core in an extremely hard, dense formation, such as gabbro.

8. The navidrill coring system indicates that high-speed mining systems have definite potential in floating vessel hard-rock applications.

\section{REFERENCES}

Shipboard Scientific Parties, 1988. Site 648. In Detrick, R., Honnorez, J., Bryan, W. B., Juteau, T., et al., Proc. ODP, Init. Repts., 106/ 109: College Station, TX (Ocean Drilling Program), 35-134.

Date of initial receipt: 9 August 1988

Date of acceptance: 9 August 1988

Ms 118A-108 